\title{
Average and Small Signal Modeling of Negative-Output KY Boost Converter in CCM Operation
}

\author{
Faqiang Wang, ${ }^{1}$ Jing $\mathrm{Li}^{2}$, and Xikui $\mathrm{Ma}^{1}$ \\ ${ }^{1}$ State Key Laboratory of Electrical Insulation and Power Equipment, School of Electrical Engineering, Xi'an Jiaotong University, \\ Xian 710049, China \\ ${ }^{2}$ Xian Institute of Space Radio Technology, Xian 710100, China
}

Correspondence should be addressed to Faqiang Wang; eecjob@126.com

Received 5 February 2014; Revised 30 March 2014; Accepted 1 April 2014; Published 23 April 2014

Academic Editor: Cristian Toma

Copyright (C) 2014 Faqiang Wang et al. This is an open access article distributed under the Creative Commons Attribution License, which permits unrestricted use, distribution, and reproduction in any medium, provided the original work is properly cited.

\begin{abstract}
Negative-output KY Boost converter, which can obtain the negative output voltage and could be driven easily, is a good topology to overcome traditional Boost and Buck-Boost converters and it is believed that this converter will be widely used in engineering applications in the future. In this study, by using the averaging method and geometrical technique, the average and small signal model of the negative-output KY Boost converter are established. The DC equilibrium point and transfer functions of the system are derived and analyzed. Finally, the effectiveness of the established model and the correctness of the theoretical analysis are confirmed by the circuit experiment.
\end{abstract}

\section{Introduction}

In recent years, exploring new topologies of DC-DC converters has attracted much attention of many researchers since it plays an important role in DC-DC switching power supplies to improve their performance, and different kinds of DC-DC converters have been proposed [1-9], such as Buck converter [1, 2], Boost converter [3], Buck-Boost converter [3], Cuk converter [3], Sepic converter [4], Luo converter [5], Superbuck converter [6], and single-inductor-multipleoutput converter $[7,8]$. Among them, a good topology of DCDC converter, named negative-output KY Boost converter, has been proposed by Hwu et al. in 2009 [9]. For this new converter, it can obtain negative-output voltage; that is, the polarity of output voltage is in contrast to its input voltage so that it makes up the drawbacks of the traditional Boost converter who obtain the positive output voltage only. Additionally, this new converter could be driven easily since its power switch is connected to ground directly. Therefore, to obtain the negative-output voltage, this new converter is superior to the traditional Buck-Boost converter since the latter one is floating. Accordingly, it is believed that the negative-output KY Boost converter will gain the popularity in the field of needing the negative electricity source, which is indispensable for the audio amplifier, signal generator, or data transmission interface and so forth. Therefore, modeling and analysis of this new converter are an important and valuable work for its real designing in practical engineering. But, until now, there are only a few studies on this new converter $[9,10]$. For example, in [9], the negative-output KY Boost converter and its operational principle have been presented. Under the assumption that the energy-transferring capacitor is large enough to keep the voltage on itself constant at the output voltage, the DC equilibrium point of the negative-output $\mathrm{KY}$ Boost converter has been derived; that is, the DC output voltage is equal to the negative DC input voltage over the results of one minus the DC duty cycle. In [10], the discrete model of the voltage-controlled negative-output KY Boost converter has been derived for investigating its stability and bifurcation, and the result indicates that the energy-transferring capacitor has an important influence on its dynamical behaviors; that is, the energy-transferring capacitor is bigger; the output voltage ripple is smaller whereas the instability region is larger. Thus, a compromise must be done when choosing the energy-transferring capacitor. So, the assumption in [9] is only an extreme case. If the condition of this extreme 


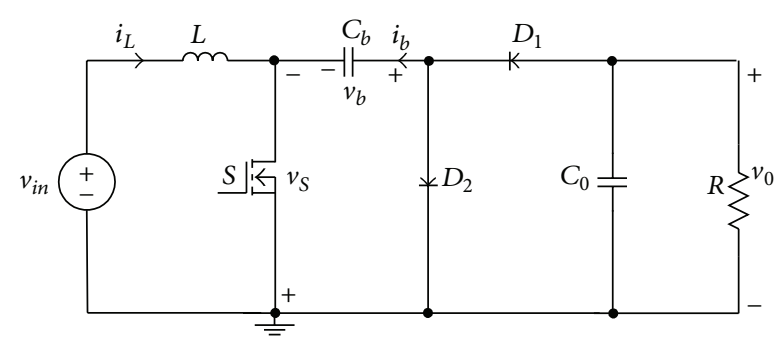

FIGURE 1: Circuit schematic of negative-output KY Boost converter.

case is not satisfied, the result about the DC equilibrium point in [9] will not be accurate, and this point will be investigated in this paper by establishing the average model of the negative-output KY Boost converter. Moreover, the small signal model of the negative-output KY Boost converter is derived and corresponding transfer functions are also presented, analyzed, and confirmed.

The rest of this paper is organized as follows. In Section 2, the circuit operation, mathematical model, and some PSIM simulations of the negative-output KY Boost converter are briefly given. In Section 3, by using the averaging method and geometrical technique, the average and small signal model of the system are established. The corresponding transfer functions are also derived and analyzed. In Section 4, the circuit experimental results are given for confirmation. Finally, some concluding remarks and comments are given in Section 5.

\section{Circuit Operation, Mathematical Model, and PSIM Simulations}

The circuit schematic of the negative-output KY Boost converter is shown in Figure 1. It consists of one input voltage $v_{\text {in }}$, one power switch $S$, two diodes: $D_{1}$ and $D_{2}$, one energytransferring capacitor $C_{b}$, one input inductor $L$, one output capacitor $C_{0}$, and one load $R$. Note that the power switch $S$ is directly controlled by the PWM signal $v_{d}$ and all the components are assumed as ideal. The current through $L$ and $C_{b}$ are defined as $i_{L}$ and $i_{b}$, respectively. The voltage across $C_{b}, C_{0}$, and $S$ is defined as $v_{b}, v_{0}$, and $v_{S}$, respectively. Also, this paper only takes the continuous conduction mode (CCM) operations into consideration, in which there are two operation modes (Figure 2) in this converter. The circuit parameters here are chosen as $v_{\text {in }}=8 \mathrm{~V}, L=1 \mathrm{mH}, C_{b}=2 \mu \mathrm{F}$, $C_{0}=40 \mu \mathrm{F}, R=100 \Omega, G=1 / R, f=25 \mathrm{kHz}, T=1 / f$, and $D=0.5$.

Mode 1 (Figure 2(a)) shows that the power switch $S$ is turned on and the diode $D_{1}$ is conducted whereas the diode $D_{2}$ is opened. Accordingly, the voltage across the inductor $L$ is equal to the input voltage $v_{\text {in }}$, thereby causing the inductor $L$ to be magnetized. The voltage across the energy-transferring capacitor $C_{b}$ is the same as the voltage across the output capacitor $C_{0}$. The sum of the current through the energytransferring capacitor $C_{b}$, the current through the output capacitor $C_{0}$, and the current through the load $R$ equals zero.
Therefore, the mathematical model for this mode can be derived as follows:

$$
\begin{aligned}
& \frac{d i_{L}}{d t}=\frac{v_{\text {in }}}{L}, \quad \frac{d v_{0}}{d t}=-\frac{i_{b}}{C_{0}}-\frac{v_{0}}{R C_{0}}, \\
& \frac{d v_{b}}{d t}=\frac{i_{b}}{C_{b}}, \quad v_{b}=v_{0} .
\end{aligned}
$$

Mode 2 (Figure 2(b)) shows that the power switch $S$ is turned off and the diode $D_{1}$ is opened whereas the diode $D_{2}$ is conducted. In this mode, the input voltage $v_{\text {in }}$ plus the voltage across the energy-transferring capacitor $C_{b}$ equals the voltage across the inductor $L$. The current through the output capacitor $C_{0}$ plus the current through the load $R$ equals zero. The current through the energy-transferring capacitor $C_{b}$ plus the current through the inductor $L$ equals zero. Thus, the mathematical model for this mode can be derived as follows:

$$
\begin{aligned}
& \frac{d i_{L}}{d t}=\frac{v_{\text {in }}+v_{b}}{L}, \quad \frac{d v_{0}}{d t}=-\frac{v_{0}}{R C_{0}}, \\
& \frac{d v_{b}}{d t}=\frac{i_{b}}{C_{b}}, \quad i_{b}=-i_{L} .
\end{aligned}
$$

According to Figure 1 and using PSIM which is widely used in power electronics and motor drives simulating $[11,12]$, the time-domain waveforms for the voltage $v_{b}, v_{0}$, and $v_{S}$ can be obtained and shown in Figures 3(a) and 3(b), respectively. Note that the voltage $v_{S}$ reflects the PWM signal $v_{d}$. That is, if the voltage $v_{S}$ equals zero, it describes that the power switch $S$ is turned on; that is, the PWM signal $v_{d}$ is high level. But, when the power switch $S$ is turned off, that is, the PWM signal $v_{d}$ is low level, $v_{S}$ is equal to the voltage $v_{b}$. Hereafter, the average and small signal model for the negative-output KY Boost converter are going to be derived and analyzed.

\section{Derivations for Average and Small Signal Model}

By using the averaging method [13], the average model of the negative-output KY Boost converter can be derived by averaging circuit variables of the system within each switching period:

$$
\begin{aligned}
& \frac{d\left\langle i_{L}\right\rangle}{d t}=\frac{\left\langle v_{\text {in }}\right\rangle}{L}+\frac{(1-d)\left\langle v_{b}\right\rangle}{L}, \\
& \frac{d\left\langle v_{0}\right\rangle}{d t}=-\frac{\left\langle i_{b}\right\rangle d}{C_{0}}-\frac{\left\langle v_{0}\right\rangle}{R C_{0}},
\end{aligned}
$$

where $\left\langle i_{L}\right\rangle,\left\langle v_{0}\right\rangle,\left\langle v_{b}\right\rangle,\left\langle i_{b}\right\rangle$, and $\left\langle v_{\text {in }}\right\rangle$ are the average values of $i_{L}, v_{0}, v_{b}, i_{b}$, and $v_{\text {in }}$, respectively. Obviously, it is necessary to derive the expressions for $\left\langle i_{b}\right\rangle$ and $\left\langle v_{b}\right\rangle$ in (3) to obtain the average model for the negative-output KY Boost converter completely.

By applying the ampere-second balance on the capacitor $C_{b},\left\langle i_{b}\right\rangle$ can be expressed as a function of $\left\langle i_{L}\right\rangle$ to be

$$
\left\langle i_{b}\right\rangle=\frac{1-d}{d}\left\langle i_{L}\right\rangle .
$$




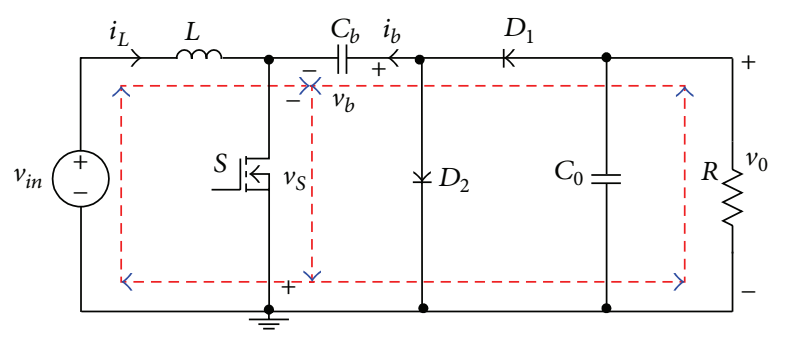

(a)

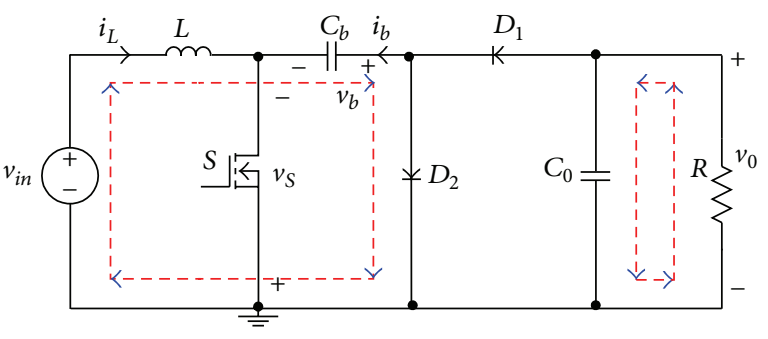

(b)

FIgure 2: Power flows for negative-output KY Boost converter. (a) Mode 1. (b) Mode 2.
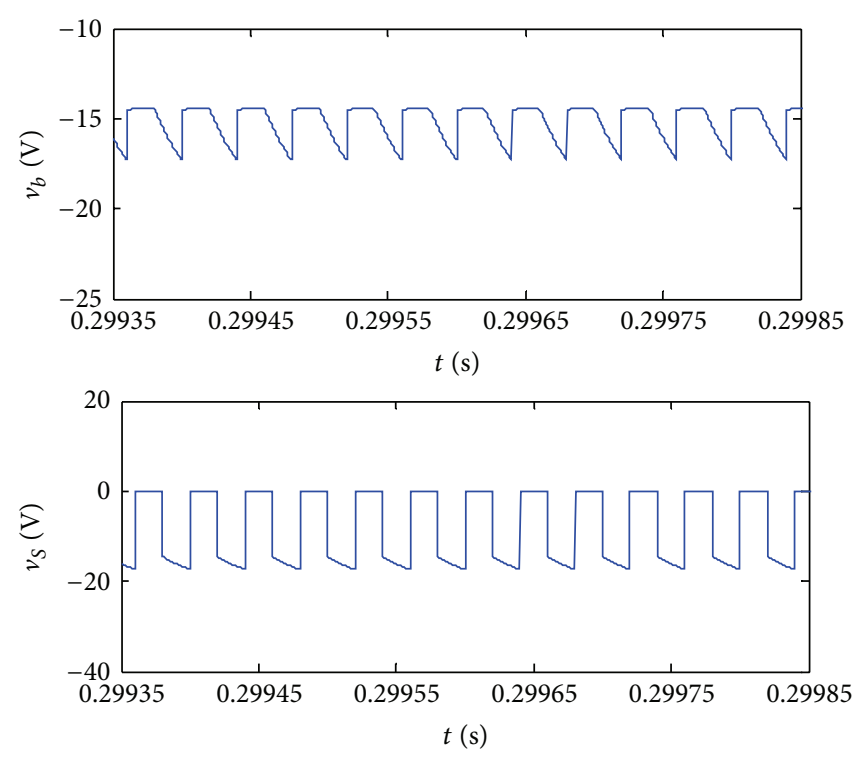

(a)
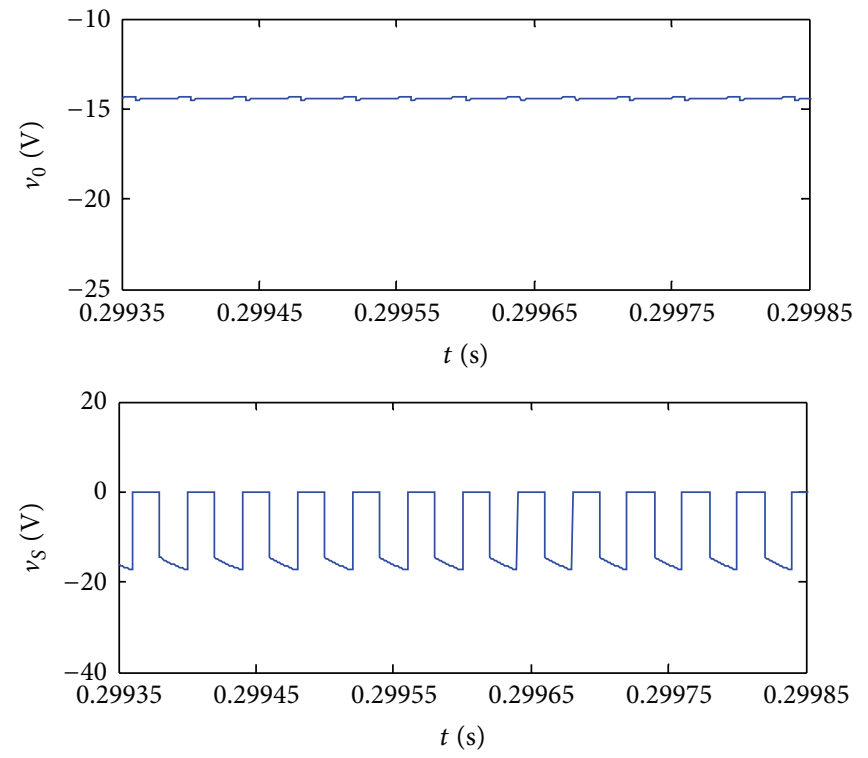

(b)

FIGURE 3: Time-domain waveforms from PSIM simulations. (a) $v_{b}$ and $v_{S}$. (b) $v_{0}$ and $v_{S}$.

Here, in order to see the relationship between the voltage $v_{b}$ and $v_{0}$ clearly and derive the expression for $\left\langle v_{b}\right\rangle$, the closedup view of the voltage $v_{0}, v_{b}$, and $v_{S}$ is replotted in Figure 4. One can see that the voltage $v_{b}$ is the same as $v_{0}$ within $(N T,(N+d) T)$ and they are denoted as $V_{N}$ at the instant $N T$ and $V_{N d}$ at $(N+d) T$. But, within $((N+d) T,(N+1) T)$, these two voltages $\left(v_{b}\right.$ and $\left.v_{0}\right)$ are not equal to each other and they are denoted as $V_{N b}$ and $V_{N 0}$ at the $(N+1) T$ before abruptly changing point, respectively. After abruptly changing point, they are denoted as $V_{N+1}$ and $V_{N}=V_{N+1}$ for the characteristic of the negative-output KY Boost converter.

Therefore, the voltage $v_{b}$ cannot be considered as equaling $v_{0}$ within the whole switching period. That is, the assumption that the energy-transferring capacitor is large enough to keep the voltage on itself at the output voltage in [9] is only the extreme case and not suitable here.

Assuming that both the voltage $v_{b}$ and voltage $v_{0}$ increase linearly within $(N T,(N+d) T)$ and $v_{b}$ decreases and $v_{0}$ increases linearly within $((N+d) T,(N+1) T)$, the following equation for $\left\langle v_{0}\right\rangle$ can be obtained by applying the geometric technique:

$$
\left\langle v_{0}\right\rangle=\frac{V_{N}+V_{N d}}{2} d+\frac{V_{N d}+V_{N 0}}{2}(1-d),
$$

where

$$
V_{N 0}=V_{N d}-\frac{\left\langle v_{0}\right\rangle}{R C_{0}}(1-d) T
$$

In the same way, the equation for $\left\langle v_{b}\right\rangle$ can also be derived and shown as follows:

$$
\left\langle v_{b}\right\rangle=\frac{V_{N}+V_{N d}}{2} d+\frac{V_{N d}+V_{N b}}{2}(1-d),
$$

where

$$
V_{N b}=V_{N d}-\frac{\left\langle i_{L}\right\rangle}{C_{b}}(1-d) T .
$$



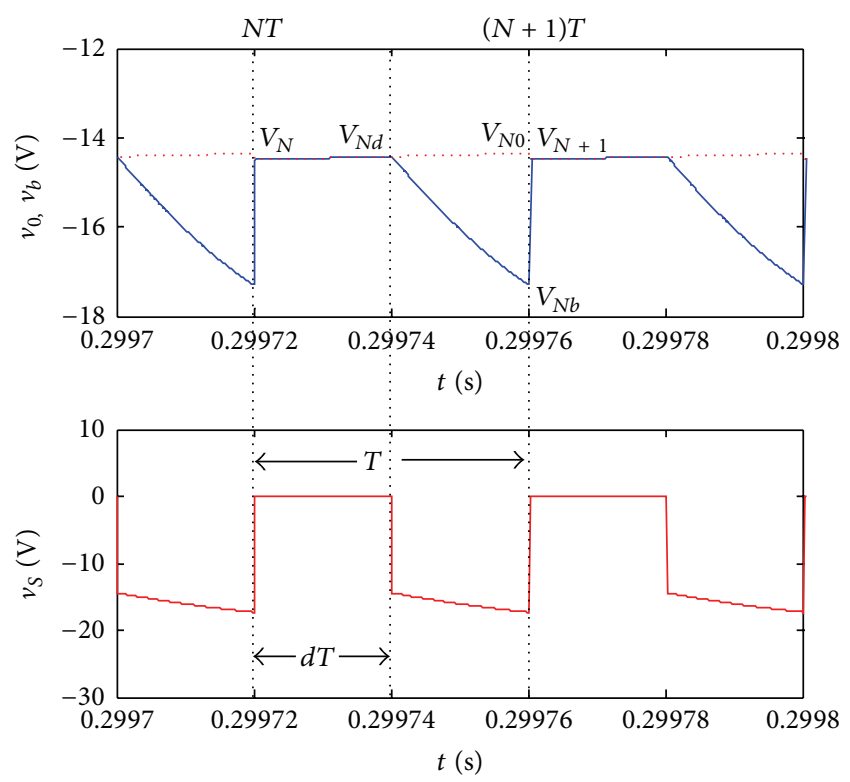

Figure 4: Closed up view of the voltage $v_{0}$ (dashed line), $v_{b}$ (solid line), and $v_{S}$.

Thus, the voltage $\left\langle v_{b}\right\rangle$ can be derived by taking (7) minus (5) and using (6) and (8), and its expression is

$$
\left\langle v_{b}\right\rangle=\left\langle v_{0}\right\rangle+\frac{\left\langle v_{0}\right\rangle(1-d)^{2}}{2 f R C_{0}}-\frac{\left\langle i_{L}\right\rangle(1-d)^{2}}{2 f C_{b}}
$$

Accordingly, the overall average equations can be obtained by substituting (4) and (9) into (3):

$$
\begin{aligned}
\frac{d\left\langle i_{L}\right\rangle}{d t}= & \frac{\left\langle v_{\text {in }}\right\rangle}{L}+\frac{(1-d)\left\langle v_{0}\right\rangle}{L} \\
& +\frac{(1-d)^{3}\left\langle v_{0}\right\rangle}{2 L f R C_{0}}-\frac{\left\langle i_{L}\right\rangle(1-d)^{3}}{2 L f C_{b}}, \\
\frac{d\left\langle v_{0}\right\rangle}{d t}= & -\frac{(1-d)\left\langle i_{L}\right\rangle}{C_{0}}-\frac{\left\langle v_{0}\right\rangle}{R C_{0}} .
\end{aligned}
$$

In order to obtain the small signal model of the system, it is necessary to use the perturbation and linearization of (10). Assume that $I_{L}, V_{0}, V_{\text {in }}$, and $D$ are the DC value of $\left\langle i_{L}\right\rangle,\left\langle v_{0}\right\rangle$, $\left\langle v_{\text {in }}\right\rangle$, and $d$, respectively, and $\hat{i}_{L}, \widehat{v}_{0}, \widehat{v}_{\text {in }}$, and $\widehat{d}$ are their small $\mathrm{AC}$ values. The following equations are also assumed to be:

$$
\begin{gathered}
\left\langle i_{L}\right\rangle=I_{L}+\hat{i}_{L} \quad \text { with } \hat{i}_{L} \ll I_{L}, \\
\left\langle v_{0}\right\rangle=V_{0}+\widehat{v}_{0} \quad \text { with } \widehat{v}_{0} \ll V_{0}, \\
\left\langle v_{\text {in }}\right\rangle=V_{\text {in }}+\widehat{v}_{\text {in }}
\end{gathered}
$$
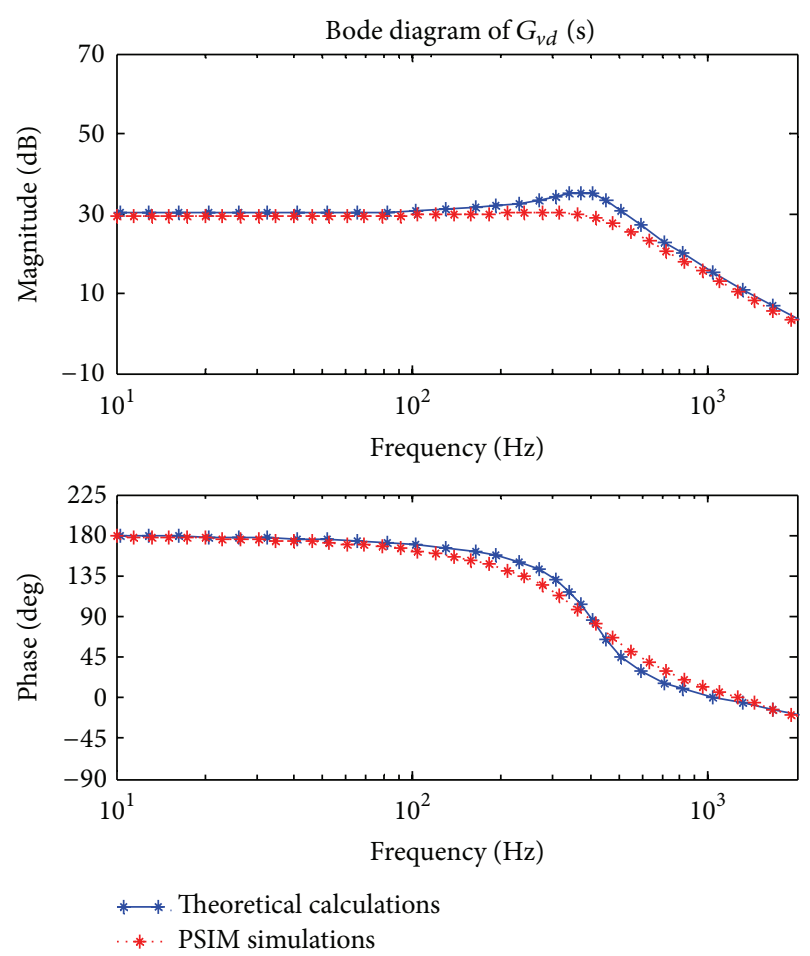

FIGURE 5: Bode diagram of $G_{v d}(s)$ from the theoretical calculations and PSIM simulations.

Therefore, the DC equilibrium point of the negativeoutput KY Boost converter can be calculated by substituting (11) into (10) and then extracting the DC values:

$$
\begin{aligned}
& V_{0}=-\frac{V_{\text {in }}}{\left(1+(1-D)^{2} / 2 f R C_{0}\right)(1-D)+(1-D)^{2} / 2 R f C_{b}}, \\
& I_{L}=\frac{V_{\text {in }}}{\left(1+(1-D)^{2} / 2 f R C_{0}\right) R(1-D)^{2}+(1-D)^{3} / 2 f C_{b}} .
\end{aligned}
$$

From (12), one can see that the DC output voltage and DC inductor current include not only the DC duty cycle and DC input voltage, but also the switching frequency $f$, load $R$, energy-transferring capacitor $C_{b}$, and output capacitor $C_{0}$. Thus, (12) are very different from the results in [9].

By substituting (11) into (10) and detaching the AC values and neglecting the second and higher order AC terms since their values are very small, the small signal model of the negative-output KY Boost converter can be obtained:

$$
\begin{aligned}
\frac{d \hat{i}_{L}}{d t}= & \frac{\widehat{v}_{\text {in }}}{L}+\frac{(1-D)(1+a) \widehat{v}_{0}}{L} \\
& -\frac{\left(3 a V_{0}-3 b I_{L}+V_{0}\right) \hat{d}}{L}-\frac{b(1-D) \hat{i}_{L}}{L}, \\
\frac{d \hat{v}_{0}}{d t}= & -\frac{(1-D) \hat{i}_{L}-\widehat{d}_{L}}{C_{0}}-\frac{\widehat{v}_{0}}{R C_{0}},
\end{aligned}
$$

where $a=(1-D)^{2} /\left(2 f R C_{0}\right)$ and $b=(1-D)^{2} /\left(2 f C_{b}\right)$. 


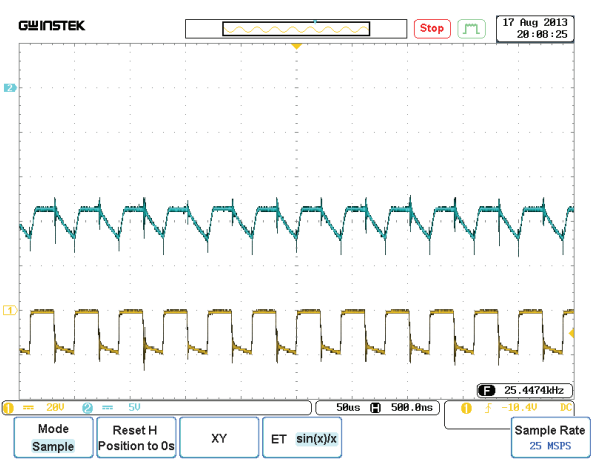

(a)

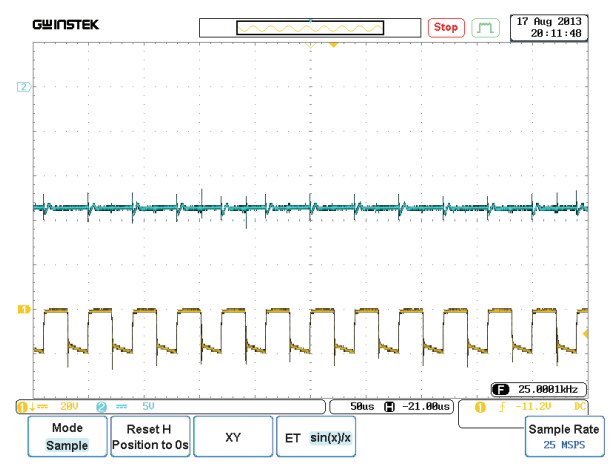

(b)

FIGURE 6: Time-domain waveforms from the circuit experiment with time scale: $50 \mu$ s/div. (a) $v_{b}$ (upper: $5 \mathrm{~V} /$ div) and $v_{S}$ (lower: $20 \mathrm{~V} /$ div), (b) $v_{0}$ (upper: $5 \mathrm{~V} / \mathrm{div}$ ), and $v_{S}$ (lower: $20 \mathrm{~V} / \mathrm{div}$ ).

Therefore, the transfer functions of the negative-output KY Boost converter can be derived by using Laplace transform on (13). Here, the transfer function from the duty cycle to the output voltage of the negative-output KY Boost converter is concerned. Its expression can be derived by making the perturbation of the input voltage be zero and then calculating $G_{v d}(s)=\widehat{v}_{0}(s) / \widehat{d}(s)$ :

$$
\begin{aligned}
& G_{v d}(s)=(s L+b(1-D)) I_{L}+\left(V_{0}+3 a V_{0}-3 b I_{L}\right)(1-D) \\
& \times\left(s^{2} L C_{0}+\left(G L+C_{0} b(1-D)\right) s\right. \\
&\left.\quad+G b(1-D)+(1+a)(1-D)^{2}\right)^{-1} .
\end{aligned}
$$

Under the given circuit parameters in Section 2, Bode diagram of $G_{v d}(s)$ is calculated and shown in Figure 5. Also, the PSIM simulations for Bode diagram of $G_{v d}(s)$, which is obtained from the original switch mode form, where no average model is required [14, 15], are shown in Figure 5. Thus, the theoretical calculations are in basic agreement with PSIM simulations. The subtle discrepancy is mainly caused by the assumption in theoretical derivations.

Additionally, the transfer functions from the input voltage to the output voltage $\left(G_{v v}(s)\right)$, the input voltage to the inductor current $\left(G_{i v}(s)\right)$, and the duty cycle to the inductor current $\left(G_{i d}(s)\right)$ are listed in appendix.

\section{Circuit Experiments}

According to Figure 1, the hardware circuit of the negativeoutput KY Boost converter is constructed by using IRFP460 and MUR1560 for realizing the power switch $S$ and two diodes $\left(D_{1}\right.$ and $\left.D_{2}\right)$, respectively. The digital oscilloscope GDS 3254 is applied to capture the measured time-domain waveforms in the probes and the Agilent E5061B LF-RF network analyzer is employed to capture the measured gain and phase in the probes. Under the given circuit parameters in Section 2, the time-domain waveforms from the circuit experiment for the voltage $v_{b}$ and $v_{S}$ are shown in Figure 6(a), and the voltage $v_{0}$ and voltage $v_{S}$ are shown in Figure 6(b). Comparing Figures 6(a) and 6(b) with Figures 3(a) and 3(b), respectively, it is found that they are in basic agreement with each other and it again demonstrates that the voltage $v_{b}$ cannot be really considered as equaling $v_{0}$ within the whole switching period.

Moreover, Bode diagram of $G_{v d}(s)$ from the circuit experiment is tested by using Agilent E5061B LF-RF network analyzer and shown in Figure 7. Also, the corresponding theoretical calculations and PSIM simulations for Bode diagram of $G_{v d}(s)$ are shown in Figure 7. Thus, they are in basic agreement with each other. The subtle discrepancy is mainly caused by the assumption in theoretical derivations and PSIM simulations.

\section{Conclusions}

By using the averaging method and the geometric technique to calculate the average value, the average model and small signal model of the negative-output KY converter are established. The obtained DC equilibrium point shows that the DC output voltage and DC inductor current are affected by not only the DC duty cycle and DC input voltage, but also the switching frequency, load, energy-transferring capacitor, and output capacitor. Moreover, the transfer function from the duty cycle to the output voltage is also derived, and the theoretical calculations and PSIM simulations are in basic agreement with the circuit experiments. The obtained results here will be helpful for designing the negative-output KY Boost converter in practical engineering.

\section{Appendix}

The transfer function from the input voltage to the output voltage of the system, that is, $G_{v v}(s)=\widehat{v}_{0}(s) / \widehat{v}_{\text {in }}(s)$, is

$$
\begin{aligned}
G_{v v}(s)=(D-1) & \left(s^{2} L C_{0}+\left(G L+C_{0} b(1-D)\right) s\right. \\
& \left.+G b(1-D)+(1+a)(1-D)^{2}\right)^{-1} .
\end{aligned}
$$



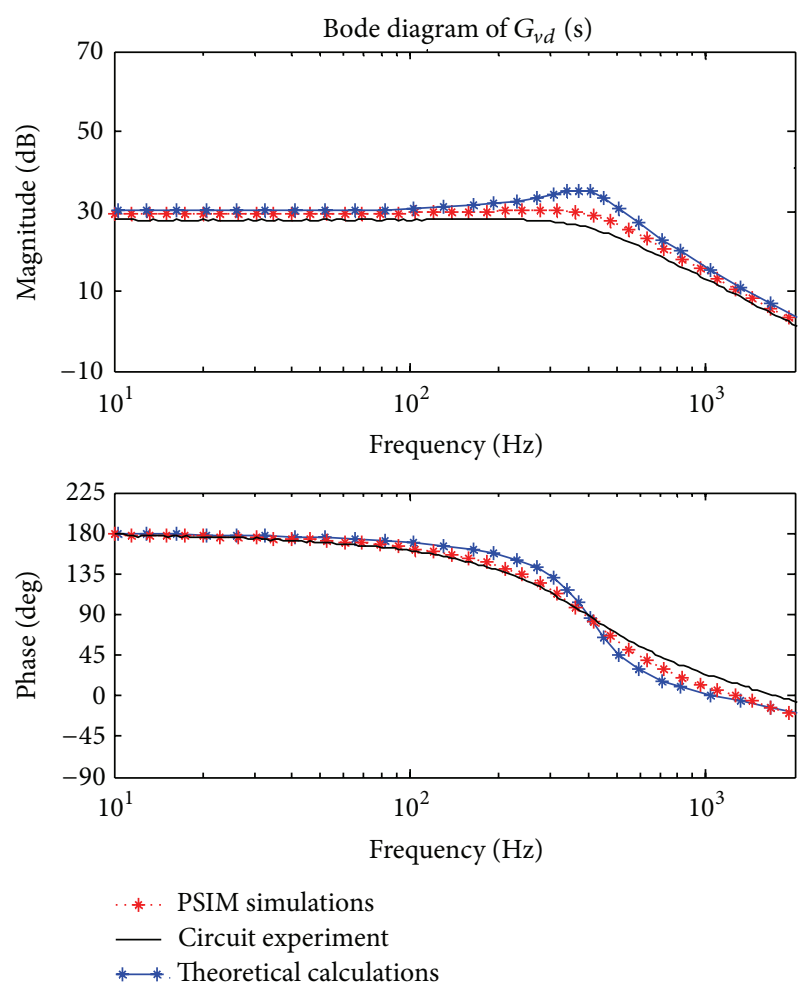

FIGURE 7: Bode diagram of $G_{v d}(s)$ from the PSIM simulations, circuit experiments, and theoretical calculations.

The transfer function from the input voltage to the inductor current of the system, that is, $G_{i v}(s)=\hat{i}_{L}(s) / \widehat{v}_{\text {in }}(s)$, is

$$
\begin{aligned}
G_{i v}(s)=\left(s C_{0}+G\right)( & s^{2} L C_{0}+\left(G L+C_{0} b(1-D)\right) s \\
& \left.+G b(1-D)+(1+a)(1-D)^{2}\right)^{-1} .
\end{aligned}
$$

The transfer function from the duty cycle to the inductor current of the system, that is, $G_{i d}(s)=\widehat{i}_{L}(s) / \widehat{d}(s)$, is

$$
\begin{aligned}
G_{i d}(s)= & \left(\left(3 b I_{L}-V_{0}-3 a V_{0}\right)\left(s C_{0}+G\right)+(1+a)(1-D) I_{L}\right) \\
& \times\left(s^{2} L C_{0}+\left(G L+C_{0} b(1-D)\right) s\right. \\
& \left.+G b(1-D)+(1+a)(1-D)^{2}\right)^{-1} .
\end{aligned}
$$

\section{Conflict of Interests}

The authors declare that there is no conflict of interests regarding the publication of this paper.

\section{Acknowledgments}

This work was supported by the National Natural Science Foundation of China (Grant nos. 51377124, 51007068, and 51221005), Foundation for the Author of National Excellent Doctoral Dissertation of PR China (Grant no. 201337), the
Program for New Century Excellent Talents in University of China (Grant no. NCET-13-0457), the Specialized Research Fund for the Doctoral Program of Higher Education of China (Grant no. 20100201120028), the Natural Science Basic Research Plan in Shaanxi Province of China (Grant no. 2012JQ7026), and the Fundamental Research Funds for the Central Universities of China (Grant no. 2012jdgz09).

\section{References}

[1] Q. M. Luo, S. B. Zhi, W. G. Lu, and L. W. Zhou, "Direct current control method based on one cycle controller for doublefrequency Buck converters," Journal of Power Electronics, vol. 12, no. 3, pp. 410-417, 2012.

[2] R. Li, T. O’Brien, J. Lee, J. Beecroft, and K. Hwang, "Analysis of parameter effects on the small-signal dynamics of Buck converters with average current mode control," Journal of Power Electronics, vol. 12, no. 3, pp. 399-409, 2012.

[3] R. W. Erickson and D. Maksimovic, Fundamentals of Power Electronics, Kluwer Academic, Boston, Mass, USA, 2nd edition, 2001.

[4] L. K. Wong and T. K. Man, "Small signal modelling of openloop SEPIC converters," IET Power Electronics, vol. 3, no. 6, pp. 858-868, 2010.

[5] F. L. Luo and H. Ye, Essential DC/DC Converters, Taylor \& Francis, New York, NY, USA, 2006.

[6] M. Karppanen, J. Arminen, T. Suntio, K. Savela, and J. Simola, "Dynamical modeling and characterization of peak-currentcontrolled superbuck converter," IEEE Transactions on Power Electronics, vol. 23, no. 3, pp. 1370-1380, 2008.

[7] D. Kwon and G. A. Rincón-Mora, "Single-inductor-multipleoutput switching DC-DC converters," IEEE Transactions on Circuits and Systems II: Express Briefs, vol. 56, no. 8, pp. 614-618, 2009.

[8] L. Benadero, V. Moreno-Font, R. Giral, and A. El Aroudi, "Topologies and control of a class of single inductor multipleoutput converters operating in continuous conduction mode," IET Power Electronics, vol. 4, no. 8, pp. 927-935, 2011.

[9] K. I. Hwu, Y. H. Chen, and W. C. Tu, "Negative-output KY boost converter," in Proceedings of the IEEE International Symposium on Industrial Electronics (IEEE ISIE '09), pp. 272-274, July 2009.

[10] F.-Q. Wang and X.-K. Ma, "Stability and bifurcation in a voltage controlled negative-output KY Boost converter," Physics Letters A, vol. 375, no. 12, pp. 1451-1456, 2011.

[11] S. Onoda and A. Emadi, "PSIM-based modeling of automotive power systems: conventional, electric, and hybrid electric vehicles," IEEE Transactions on Vehicular Technology, vol. 53, no. 2, pp. 390-400, 2004.

[12] M. Veerachary, "PSIM circuit-oriented simulator model for the nonlinear photovoltaic sources," IEEE Transactions on Aerospace and Electronic Systems, vol. 42, no. 2, pp. 735-740, 2006.

[13] R. D. Middlebrook and S. Cuk, "A general unified approach to modelling switching-converter power stages," International Journal of Electronics, vol. 42, no. 6, pp. 521-550, 1977.

[14] PSIM User's Guide, Version 9. 0, Release 3, Powersim, 2010.

[15] N. Femia, M. Fortunato, G. Petrone, G. Spagnuolo, and M. Vitelli, "Dynamic model of one-cycle control for converters operating in continuous and discontinuous conduction modes," International Journal of Circuit Theory and Applications, vol. 37, no. 5, pp. 661-684, 2009. 


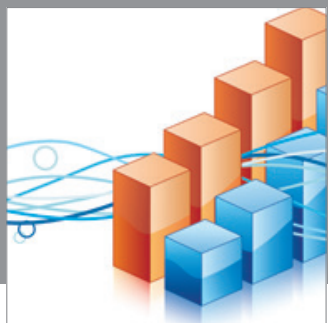

Advances in

Operations Research

mansans

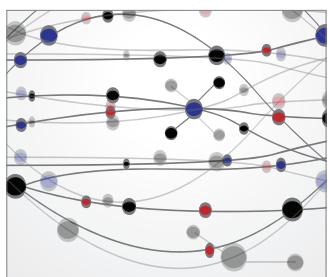

The Scientific World Journal
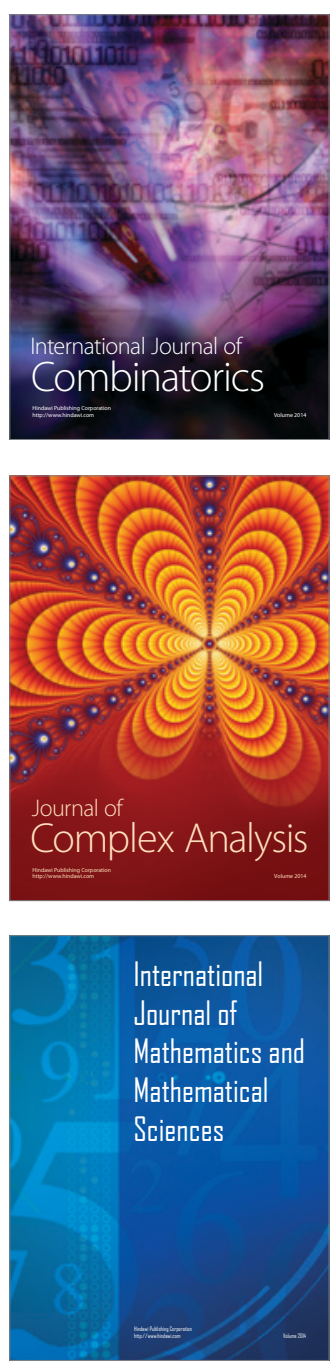
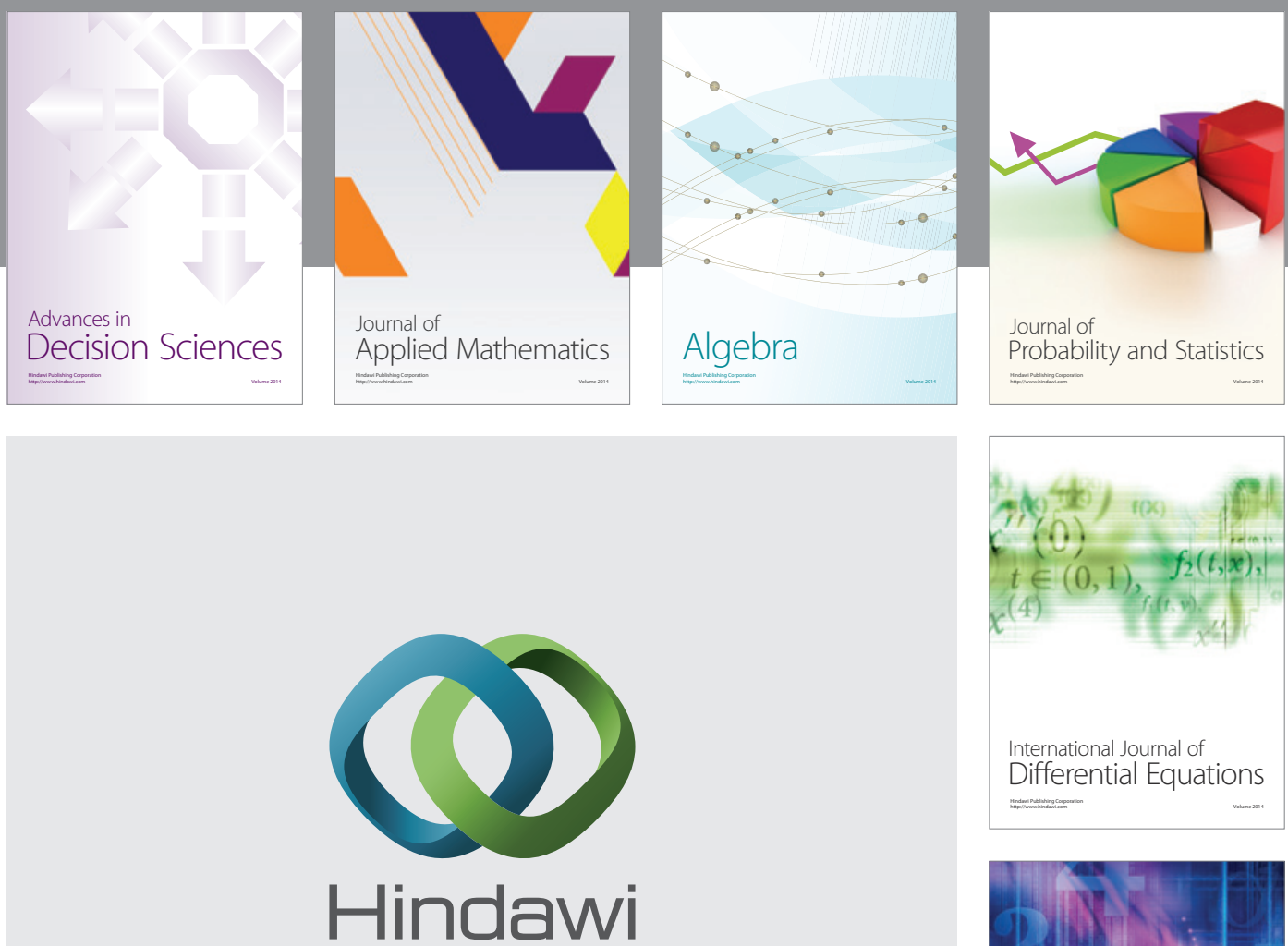

Submit your manuscripts at http://www.hindawi.com
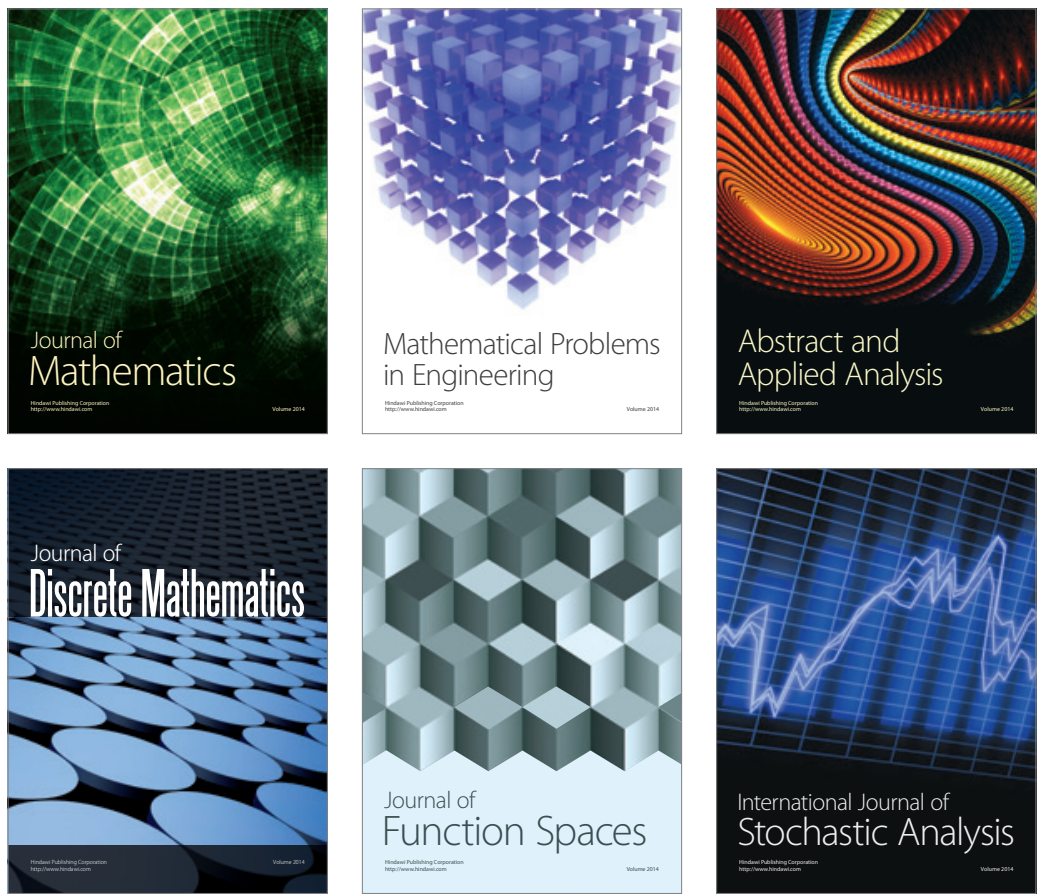

Journal of

Function Spaces

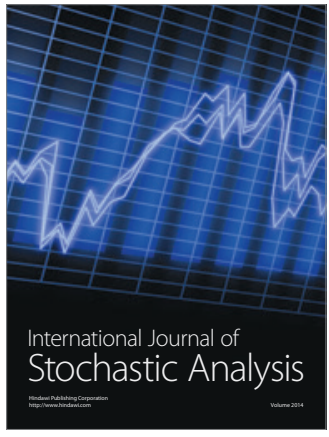

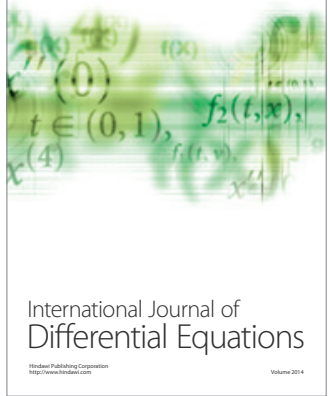
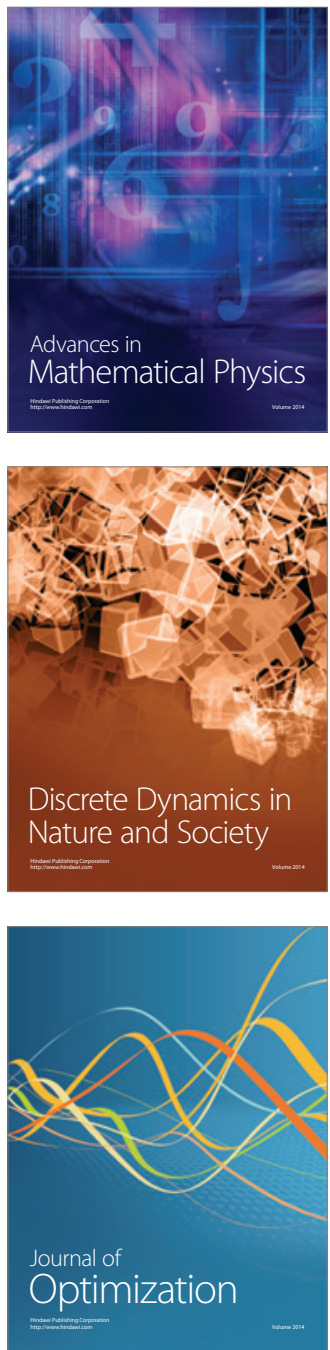